Article

\title{
Vertical Round Buoyant Jets and Fountains in a Linearly, Density-Stratified Fluid
}

\author{
Panos N. Papanicolaou ${ }^{1, *}$ and George C. Stamoulis ${ }^{2}$ \\ 1 Applied Hydraulics Laboratory, School of Civil Engineering, National Technical University of Athens, \\ 5 Heroon Polytechniou Street, 15780 Zografou, Greece \\ 2 Hydromechanics and Environmental Engineering Laboratory, Department of Civil Engineering, \\ University of Thessaly, Pedion Areos, 38334 Volos, Greece; gestamoul@gmail.com \\ * Correspondence: panospap@mail.ntua.gr; Tel.: +30-210-772-2854
}

Received: 10 November 2020; Accepted: 2 December 2020; Published: 4 December 2020

\begin{abstract}
Turbulent round buoyant jets and fountains issuing vertically into a linearly density-stratified calm ambient have been investigated in a series of laboratory experiments. The terminal (steady-state) height of rise and the mean elevation of subsequent horizontal spreading have been measured in positively buoyant jets (at source level), including pure momentum jets and plumes, as well in momentum-driven negatively buoyant jets (fountains). The results from experiments confirmed the asymptotic analysis that was based on dimensional arguments. The normalized terminal height and spreading elevation with respect to the elevation of injection of momentum-driven (positively) buoyant jets and fountains attained the same asymptotic values. The numerical results from the solution of entrainment equations, using an improved entrainment coefficient function, confirmed the results related to buoyancy dominant flows (plumes), while their predictions in momentum-driven flows were quite low if compared to measurements.
\end{abstract}

Keywords: buoyant jet; negative buoyancy; fountain; linear density gradient; stratified ambient; terminal height of rise; spreading height; entrainment coefficient; dilution

\section{Introduction}

A round buoyant jet is the flow out of a pipe or circular nozzle that discharges into a quiescent or moving volume of fluid of different density. A vertical jet is positively buoyant if the direction of flow initially is that of the effective gravity, due to the density difference between jet and ambient fluid at the elevation of discharge; otherwise, it is called a negatively buoyant jet or fountain. A positively buoyant jet rises and mixes up to the surface of a surrounding motionless fluid of higher uniform density. A (momentum-dominated) fountain rises and mixes in an ambient of uniform, lower density to an elevation where the momentum flux of the mixed fluid vanishes. Then, the flow reverses and returns to the elevation of injection.

In a density-stratified, stable, calm ambient, a vertical jet that is positively buoyant at the elevation of injection entrains and mixes with the surrounding fluid up to an elevation where the average jet density is equal to that of the ambient fluid (neutral buoyancy). From that point on, the vertical kinematic momentum flux (inertia) of the jet will force it to a higher elevation, while ambient fluid still entrains and mixes with jet fluid, until the vertical momentum flux vanishes. Then, the jet flow reverses and returns to the elevation of neutral buoyancy, where it spreads horizontally. A vertical fountain (jet negatively buoyant at injection elevation) in a stable, density-stratified ambient will rise and mix with ambient up to the elevation where its kinematic momentum flux vanishes, under the influence of reverse buoyancy. Then, the direction of motion reverses and the fluid returns to an elevation of neutral density where it spreads horizontally. The maximum steady-state elevation attained by a 
vertical jet that is initially positively buoyant or a fountain in a density-stratified ambient is defined as "the terminal height of rise" (THR), and the mean elevation of neutral density where it spreads horizontally is defined as the "spreading height" (SH).

Atmosphere and oceans are both density-stratified. When studying the initial dilution of turbulent buoyant jets which discharge in the atmosphere or in a body of water, the ambient is assumed to be motionless, since the timescale of the initial evolution of the flow is rather short. Subsequently, it may be considered as a moving body of fluid for the study of the dispersion in the horizontal spreading field which is formed.

Following the pioneering work of Morton, Taylor, and Turner [1], the mechanics of positively buoyant jets and fountains in a calm, linearly density-stratified ambient has been the subject of theoretical and experimental investigations for several decades. Vertical fountains in a uniform ambient fluid have also been studied in experiments [2,3]. Interest has been focused on the terminal rise height reached by the flow, as well as the mean spreading elevation where the mixed fluid subsequently expands horizontally. Direct applications of the results of such studies are related to the design of outfalls for the disposal of treated municipal wastewater and brine from desalination plants into the sea, as well as to the dispersion of smoke from factory stacks in the atmosphere. Further applications are the study of geophysical flows such as the motion of smoke plumes above fires, volcano eruptions, black smokers in the deep ocean, and magma chambers. Note that, after the eruptions of the Eyjafjallajökull volcano in Iceland (April-May 2010), ash and gases spread at an elevation around $7000 \mathrm{~m}$ in a very large area, causing great problems in the aviation industry for a long time.

Earlier studies of round buoyant jets and fountains in a linearly density-stratified ambient that focused on the terminal height of rise (THR) are summarized in [4]. In cases where the initial momentum of the flow dominates the buoyancy force at the injection point, the flow is characterized as momentum-driven or as jet-like. If the initial buoyancy force dominates the momentum at the injection point, the flow is characterized as buoyancy-driven or as a plume. The fountain flow is jet-like since it is a consequence of the initial jet momentum. Fischer et al. [4] using the experiments in [5,6] proposed that the normalized THR $c_{j}$ (to be defined in Section 2) for positively buoyant, momentum-driven flows (jets) is $c_{j}=3.80$, as also presented in [7]. In (positively buoyant) plumes, from the experiments in $[1,8,9],[4]$ proposed the same constant $c_{p} \approx 3.80$ ( $c_{p}$ is defined in Section 2 ) for the normalized THR, while [7] recommended a constant equal to 5 .

Experiments on positively buoyant, vertical, round jets that discharge into a linearly density-stratified fluid were implemented by [10]. The authors classified the flow into two asymptotic cases, jet-like flows and plumes, on the basis of the dimensionless parameter $M N / B$, where $M$ and $B$ are the initial specific (per unit mass) momentum and buoyancy fluxes and $N$ is the buoyancy frequency of the density stratification to be defined in Section 2. Experiments in the regime $0.80<M N / B<2.40$ regarding the THR were also reported [11] from measurements. Similar experiments were reported for a wide range of $M N / B$ by [12,13], the latter [13] including data for the mean spreading elevation of the buoyant jet. Experiments were reported by [14] for pure momentum-driven and negatively buoyant jets (fountains) in a linearly, density-stratified ambient. The authors [14] also solved the steady-state equations of motion numerically and found the predictions to be congruent with their experiments.

Recently, the spreading height of buoyant jets in a linearly density-stratified ambient was measured [15], concluding that the normalized spreading height is 1.53 when $M N / B>7$ and 2.775 when $M N / B<7$. Measurements of the velocity field of buoyant jets in linearly stratified ambient were performed [16] using particle image velocimetry (PIV). The terminal rise height in plume-like flows was measured, along with the turbulence parameters that were evaluated for modeling.

The model proposed in [1] was extended [17] to compute the THR and SH in geophysical flows on Earth, as well as on other planets. An attempt was made to connect the rise height to a plume length scale ( $L_{\mathrm{p}}$ defined in next chapter), where both are normalized by the plume diameter, via the coefficient of entrainment that is variable in the range 0.05 to 0.16 . This normalization does not comply with dimensional arguments presented in the next section. 
The scope of the present investigation is to provide a systematic new set of data regarding the THR and SH of buoyant jets and fountains in a linearly density-stratified ambient and compare it to earlier experiments. Following the dimensional arguments (see next section), the experiments extend to a range of the dimensionless parameter $M N / B$ that includes the two asymptotic regimes of initially jet-like flows and plumes, as well as the transition in between. Emphasis is given to the spreading height (SH) that is a very important parameter in the dispersion of buoyant jets in a stratified ambient, where available data are limited. An integral model using an improved entrainment coefficient function derived in Appendix A from the entrainment equations is applied, in an effort to match the results obtained from the experiments. The entrainment function obtains a reduced coefficient if compared to that of a simple jet, when the buoyancy acts against the movement, in accordance with the results in $[18,19]$.

\section{Dimensional Analysis-Review of Earlier Experiments}

A round vertical (positively) buoyant jet of density $\rho_{o}$ and uniform velocity $W$ discharges vertically into an infinite volume of calm, linearly density-stratified fluid. The initial jet volume flux $Q$, specific (per unit mass) momentum $M$, and buoyancy $B$ fluxes with dimensions $\mathrm{L}^{3} / \mathrm{T}, \mathrm{L}^{4} / \mathrm{T}^{2}$, and $\mathrm{L}^{4} / \mathrm{T}^{3}$, respectively, are calculated as follows:

$$
Q=W=\frac{\pi D^{2}}{4} W, \quad M=Q W, \quad B=g_{o}^{\prime} Q ; g_{o}^{\prime}=\frac{\rho_{a}-\rho_{o}}{\rho_{o}} \mathrm{~g},
$$

where $\rho_{a}$ is the density of the ambient fluid at the jet nozzle elevation. The buoyancy frequency $N$ of the linearly density-stratified ambient with dimensions $\mathrm{T}^{-1}$ is computed from

$$
N^{2}=-\frac{g}{\rho_{o}} \frac{\mathrm{d} \rho}{\mathrm{d} z} .
$$

Let us assume fully developed turbulent flow and adopt the Boussinesq approximation (density differences do not exceed 5\%). The terminal (steady-state) height of rise $Z$ is related to the initial flow parameters with a functional relationship $Z=Z(Q, M, B, N)$. Far from the ejection point, the jet volumetric flow rate is much greater than the initial one, such that $Q$ may be neglected [4]; thus, $Z=$ $Z(M, B, N)$. Two length scales $L_{j}$ and $L_{p}$ may be defined, one using the initial jet momentum flux and $N$ and the other using the initial buoyancy flux and $N[1,4,9,20]$, as follows:

$$
L_{j}=\frac{M^{1 / 4}}{N^{1 / 2}} \text { and } L_{p}=\frac{B^{1 / 4}}{N^{3 / 4}} .
$$

The jet is characterized initially as momentum (inertia)-driven or as buoyancy-driven, from the ratio of the inertia to buoyancy forces that is the initial densimetric Froude number [4] $F r_{o}=W /\left(g^{\prime}{ }_{0} D\right)^{1 / 2}$, $g^{\prime}{ }_{o}=\left(\rho_{a}-\rho_{o}\right) / \rho_{o}$. Thus, the flow can be classified into four categories on the basis of the initial momentum and buoyancy fluxes $B$ and $M$, respectively (or on $F r_{o}$ ), as well as the (initial) density difference between jet $\rho_{o}$ and ambient fluid $\rho_{a}$ at nozzle elevation: (i) jet-like flow when the momentum flux is dominant and $\rho_{o} \leq \rho_{a}$ or $F r_{\mathrm{o}}$ is very large, (ii) plume-like flow, when the buoyancy flux is dominant and $\rho_{o} \leq \rho_{a}$ or $F r_{o} \rightarrow 1$, (iii) buoyant jet (forced plume) flow when momentum and buoyancy fluxes affect the flow equally and $\rho_{o} \leq \rho_{a}$, and (iv) fountain flow when the momentum flux is dominant and $\rho_{o} \geq \rho_{a}(B<0)$.

(i) A jet-like discharge $\left(B \approx 0, \rho_{o} \leq \rho_{a}\right)$ will rise up to an elevation $Z=Z(M, N)$ that is only a function of the initial specific momentum flux $M$ and the buoyancy frequency $N$, thus leading to a dimensionless elevation,

$$
\mathrm{Z}\left(\frac{N^{2}}{M}\right)^{1 / 4}=\frac{Z}{L_{j}}=c_{j}
$$


which must be constant.

(ii) A plume $\left(M \approx 0, \rho_{o} \leq \rho_{a}\right)$, will rise up to a dimensionless elevation,

$$
Z \frac{N^{3 / 4}}{B^{1 / 4}}=\frac{Z}{L_{p}}=c_{p},
$$

which must also be constant.

(iii) A buoyant jet with initial kinematic momentum and buoyancy fluxes $M$ and $B$, respectively, of similar strength that discharges into an ambient fluid with linear density stratification of buoyancy frequency $N$ will rise to an elevation $Z$ that is a function of $M, B$, and $N$. Then, the normalized rise height will attain a functional form,

$$
\frac{Z}{L_{p}} \text { or } \frac{Z}{L_{j}}=f\left(\frac{M}{B} N\right),
$$

where $M N / B$ is a characteristic dimensionless parameter. In asymptotically jet-like flows $(M>>$ $B), M N / B>>1$ and Equation (4) is valid, while, in plumes, $M N / B<1$ and Equation (5) is valid. If $M N / B>>1$, dividing both sides of Equation (4) by $L_{p}$ obtains

$$
\frac{Z}{L_{p}}=c_{j} \frac{L_{j}}{L_{p}}=c_{j}\left(\frac{M}{B} N\right)^{1 / 4}
$$

meaning that the dimensionless jet rise $Z / L_{p}$ is proportional to $(M N / B)^{1 / 4}$. Similarly, in plumes $(M N / B<1)$,

$$
\frac{Z}{L_{j}}=c_{p} \frac{L_{p}}{L_{j}}=c_{p}\left(\frac{M}{B} N\right)^{-1 / 4} .
$$

The analysis presented above is also valid if we substitute the terminal rise height $Z$ with spreading elevation $Z_{S}$, giving $Z_{S} / L_{j}=$ constant for jet-like flows and $Z_{S} / L_{p}=$ constant for plumes.

(iv) A fountain is the flow when the initial momentum flux is large but the buoyancy flux $B$ is negative (opposite to the direction of motion). In a uniform, calm ambient, the normalized terminal height of rise of a turbulent fountain is constant [21],

$$
\frac{Z}{l_{M}}=C,
$$

if the length scale $l_{M}=M^{3 / 4} /|B|^{1 / 2}[2,4]$ is large, or alternatively when the initial jet Richardson number $R i_{o}=Q\left|B^{1 / 2}\right| / M^{5 / 4}<<1[21]$. For fountains (large $l_{M}$ ) in a linearly density-stratified ambient, the asymptotic normalized terminal height of rise $Z$ is a function of $M$ and $N$ only and, therefore, $Z / L_{j}$ takes a limiting value as shown from Equation (4). Thus, for large values of the parameter $M N /|B|, Z / L_{j}=$ constant, regardless of the sign of $B$. Rearranging the terms in Equation (4) gives

$$
\frac{Z}{l_{M}}=c_{j} \frac{L_{j}}{l_{M}}=c_{j}\left(\frac{M N}{B}\right)^{-1 / 2} \text {. }
$$


When the stratification parameter $N$ is small $(N \rightarrow 0, M N / B<<1)$ the ambient fluid asymptotically can be considered as homogeneous, and the turbulent fountain will reach a terminal rise height so that Equation (9) is fulfilled, i.e.,

$$
\frac{Z}{l_{M}}=C \Rightarrow \frac{Z}{L_{j}}=C \frac{l_{M}}{L_{j}}=C\left(\frac{M N}{B}\right)^{1 / 2} \text { or alternatively } \frac{Z}{L_{p}}=C\left(\frac{M N}{B}\right)^{3 / 4} .
$$

Note that, in the case of a fountain, the spreading height (SH) elevation obeys the dimensional arguments made for the terminal rise height (THR).

An average dilution at elevation $z$ is the ratio $S=\mu(z) / Q$ of the local jet volume flux $\mu(z)$ to the initial one $Q$. Following the same procedure as in the previous paragraphs, if the momentum is initially dominant $(M N / B>>1$, jet-like flow), the normalized volume flux may be obtained as

$$
\frac{\mu(Z) N^{1 / 2}}{M^{3 / 4}}=d_{j} \text { or } \frac{\mu(Z) N^{5 / 4}}{B^{3 / 4}}=d_{j}\left(\frac{M N}{B}\right)^{3 / 4} .
$$

If the buoyancy is dominant $(M N / B<1$, plume-like flow $)$,

$$
\frac{\mu(Z) N^{5 / 4}}{B^{3 / 4}}=d_{p} \text { or } \frac{\mu(Z) N^{1 / 2}}{M^{3 / 4}}=d_{p}\left(\frac{M N}{B}\right)^{-3 / 4}
$$

\begin{tabular}{|c|c|c|c|c|}
\hline \multicolumn{5}{|c|}{$M N / B>>1$} \\
\hline Jets and fountains & $\frac{Z}{L_{j}}=c_{j}$ & $\frac{Z}{L_{p}}=c_{j}\left(\frac{M N}{B}\right)^{1 / 4}$ & $\frac{Z}{l_{M}}=c_{j}\left(\frac{M N}{B}\right)^{-1 / 2}$ & $\frac{\mu(\mathrm{Z}) N^{1 / 2}}{M^{3 / 4}}=d_{j}$ \\
\hline \multicolumn{5}{|c|}{$M N / B<1$} \\
\hline Plumes & $\frac{Z}{L_{j}}=c_{p}\left(\frac{M N}{B}\right)^{-1 / 4}$ & $\frac{Z}{L_{p}}=c_{p}$ & $\frac{Z}{l_{M}}=c_{p}\left(\frac{M N}{B}\right)^{-3 / 4}$ & $\frac{\mu(Z) N^{5 / 4}}{B^{3 / 4}}=d_{p}$ \\
\hline
\end{tabular}

where $d_{j}$ and $d_{p}$ are constants. The results from the asymptotic analysis are summarized in Table 1.

Table 1. Summary of the asymptotic relationships resulting from dimensional analysis.

Data from earlier experiments regarding the THR and SH were normalized and plotted together to justify the findings from dimensional analysis and evaluate the constants. The constants of proportionality from different experiments are shown in Table 2. The parameters presented in this section are used for comparison with present data. The descriptions "ortho" and "round" for the data by Wong and Wright [10] refer to the shape of the horizontal cross-section of the dispersion tank they employed, which was orthogonal and circular, respectively, for the two different sets of experiments they implemented. 
Table 2. Evaluation of the dimensionless parameters from earlier experiments.

\begin{tabular}{|c|c|c|c|c|c|c|c|}
\hline Author & $Z / L_{j}$ & $Z_{S} / L_{j}$ & $Z / L_{p}$ & $Z_{S} / L_{p}$ & $d_{j}$ & $d_{p}$ & Comments \\
\hline Morton, Taylor, and Turner [1] ${ }^{1}$ & & & $3.81 \pm 0.25$ & & & & Plume \\
\hline Fan [5] & $3.41 \pm 0.13$ & & & & & & $M N / B>10$ \\
\hline Abraham and Eysink [11] & & & $3.63 \pm 0.20$ & & & & $M N / B=0.80-2.40$ \\
\hline Wong and Wright [10] for rectangular tank & $3.72 \pm 0.17$ & & $4.50 \pm 0.46$ & & $0.77 \pm 0.14$ & $0.78 \pm 0.11$ & $\begin{array}{c}M N / B>10 \\
M N / B<1\end{array}$ \\
\hline Wong and Wright [10] for circular tank & $3.23 \pm 0.09$ & & $4.28 \pm 0.37$ & & $0.68 \pm 0.03$ & $0.84 \pm 0.12$ & $\begin{array}{c}M N / B>10 \\
M N / B<1\end{array}$ \\
\hline Wong and Wright [10] for all data & $3.60 \pm 0.27$ & & $4.46 \pm 0.44$ & & $0.74 \pm 0.12$ & $0.81 \pm 0.11$ & $\begin{array}{c}M N / B>10 \\
M N / B<1\end{array}$ \\
\hline Papanicolaou et al. [12] & $3.46 \pm 0.16$ & & $4.60 \pm 0.39$ & & & & $\begin{array}{c}M N / B>10 \\
M N / B<1\end{array}$ \\
\hline Bloomfield and Kerr [14] ${ }^{1,2}$ & $3 \pm 0.23(3.15) *$ & $\begin{array}{c}1.53 \pm 0.10 \\
(1.52) *\end{array}$ & & & & & $B=0$ \\
\hline Bloomfield and Kerr [14] ${ }^{1,3}$ & $2.88 \pm 0.10$ & $1.35 \pm 0.11$ & & & & & $B<0$ \\
\hline Konstantinidou and Papanicolaou [13] & $3.55 \pm 0.16$ & $2.38 \pm 0.39$ & $3.97 \pm 0.29$ & $2.99 \pm 0.29$ & & & $\begin{array}{c}M N / B>10 \\
M N / B<1\end{array}$ \\
\hline Richards et al. [15] & & $1.50(1.89)^{*}$ & & $2.7(2.78)^{*}$ & & & $M N / B=0.4 \div 46$ \\
\hline Zhang et al. [16] & & & $3.47 \pm 0.26$ & & & & $M N / B<2.80$ \\
\hline Fischer et al. [4] & 3.80 & & 3.80 & & & & Proposed values \\
\hline Chen and Rodi [7] & 3.80 & & 5.00 & & & & Proposed values \\
\hline
\end{tabular}

${ }^{1}$ Including virtual origin distance; ${ }^{2}$ zero buoyancy flux at source; ${ }^{3}$ fountain; ${ }^{~}$ linear fit. 
The normalized THR $Z / L_{j}$ and $Z / L_{p}$ are plotted versus the dimensionless parameter $M N / B$ in Figure 1. From Figure $1 a$, it is evident that, when $M N / B>10$, the normalized THR $Z / L_{j}$ is constant, in accordance with dimensional analysis, with an average value around $c_{j} \approx 3.50$ according to all authors but [14]. From Figure $1 b$, it is clear that, when $M N / B<1$, the normalized THR $Z / L_{p}$ is a constant, congruent with dimensional analysis regarding initially plume-like flows, with an average constant from the data presented of $c_{p} \approx 4.35$, greater than those measured in $[1,11,16]$. Note that $[1,14]$ added the distance $z_{0}$ of virtual origin to the THR, estimated to be located $5 \mathrm{~cm}$ and $1 \mathrm{~cm}$ upstream from the pipe outlet, respectively. Data from other authors did not involve $z_{0}$, including Fan's [5] data, from which we subtracted 6.2 jet diameters.

(a)

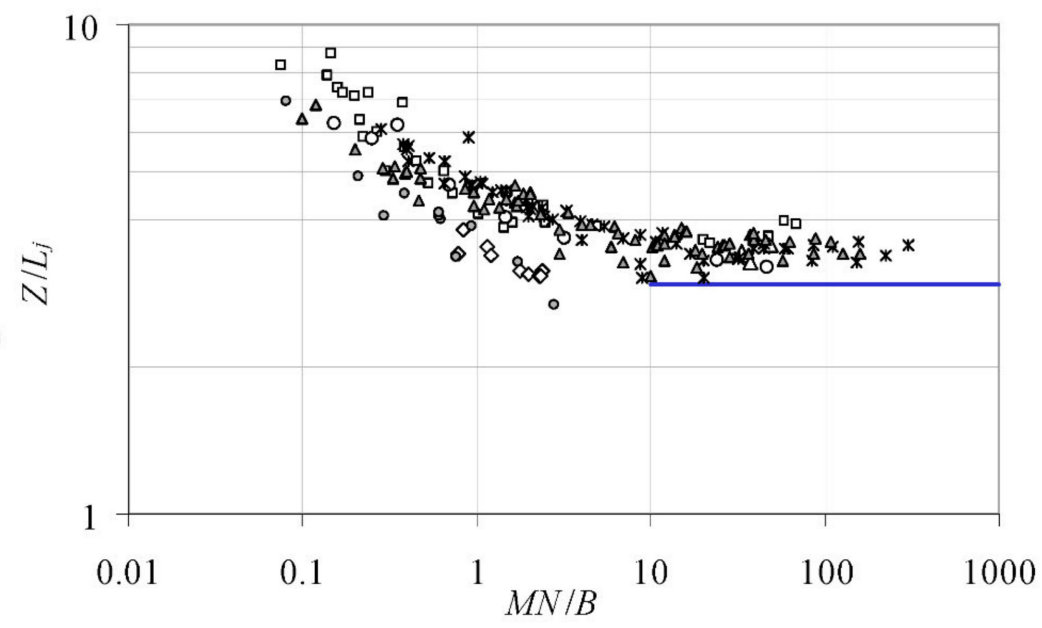

$\triangle$ Fan [5]

$\diamond \mathrm{A} \& \mathrm{E}[11]$

- W\&W [10] ortho

○ W\&W [10] round

* Pap. et al [12]

$\triangle \mathrm{K} \& \mathrm{P}[13]$

- B \& K [14]

- Zhang et al [16]

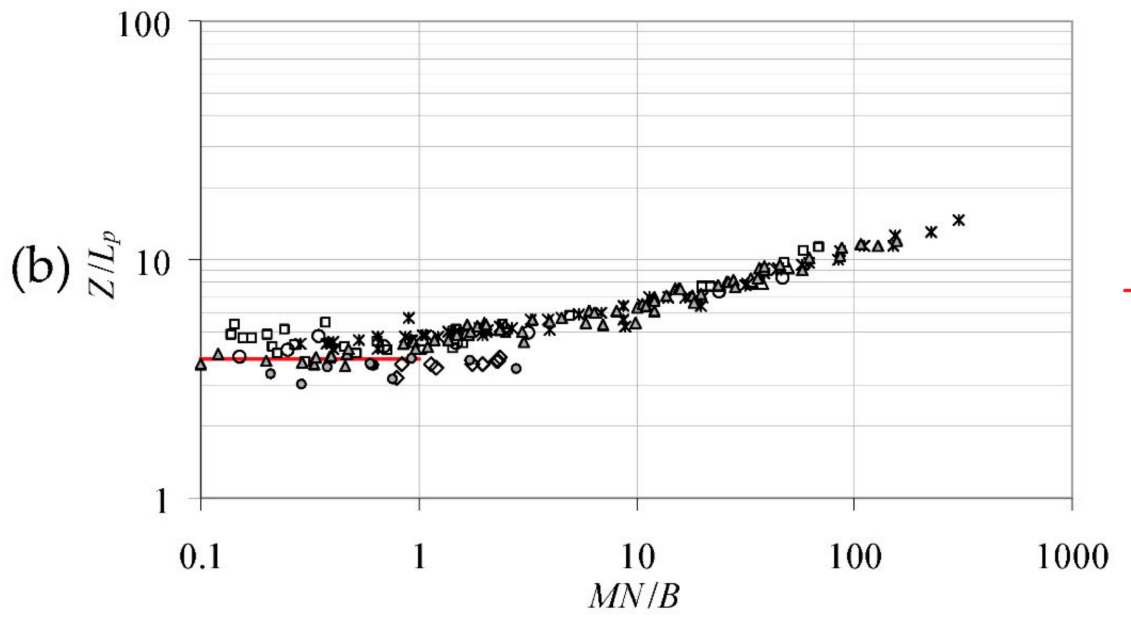

$\Delta$ Fan [5]

$\diamond \mathrm{A} \& \mathrm{E}[11]$

- W\& W [10] ortho

○ W \& W [10] round

* Pap et al. [12]

$\triangle \mathrm{K} \& \mathrm{P}[13]$

- MTT [1]

- Zhang et al. [16]

Figure 1. Normalized terminal rise height (a) $Z / L_{j}$ and (b) $Z / L_{p}$ versus the dimensionless parameter $M N / B$ from earlier experiments.

\section{Experiments-The Integral Model}

Experiments were performed in a tank made of $1.25 \mathrm{~cm}$ thick Lucite with horizontal dimensions $0.90 \mathrm{~m} \times 0.60 \mathrm{~m}$ and $0.80 \mathrm{~m}$ deep. An overflow around the top was used for excess fluid removal. The jet fluid was dyed with food dye, and the flow was illuminated with two $1000 \mathrm{~W}$ flood lights through a $5 \mathrm{~mm}$ thick panel of milky-white plexiglass, placed behind the rear window to diffuse the light uniformly. In the front and back (opposite) Lucite windows, square grids of $5 \mathrm{~cm} \times 5 \mathrm{~cm}$ were drawn. For a vertical jet placed at the mid-plane of the tank, the terminal height of rise (THR) and mean spreading height ( $\mathrm{SH}$ ) were the average values read in the front and rear grid [22]. The linear density gradient was obtained using the "two-tank technique" [23]. Two similar tanks connected with a pipe were used, the first filled with fresh water and the other with an aqueous salt $(\mathrm{NaCl})$ solution. 
Heavy fluid withdrawn from the continuously stirred second tank at small flow rates was pumped toward two floating surface spreaders positioned inside the dispersion tank. In this manner, lighter fluid was continuously added on the surface of the underlying heavier one, until the dispersion tank was filled up to the elevation of the overflow.

Four nozzles with diameters $0.5,0.75,1$, and $1.5 \mathrm{~cm}$ were used to create the buoyant jets. They were mounted at the lower end of a jet plenum made of a $200 \mathrm{~mm}$ long piece of polyvinyl chloride (PVC) pipe with an inner diameter of $40 \mathrm{~mm}$. A $2 \mathrm{~cm}$ long cylinder of sponge and a subsequent $6 \mathrm{~cm}$ long honeycomb section were set inside the jet plenum, to destroy any large eddies launched at the upstream end of it from the supply pipe and reduce the jet turbulence intensity. The inner side of all nozzles (inside the jet plenum) was rounded in order to provide smooth transition from the $40 \mathrm{~mm}$ pipe diameter to the size of the nozzle diameter, thus producing a uniform velocity profile at the exit $[24,25]$.

When the stratification tank was filled up to the overflow, the surface spreaders were removed. The density profile was measured $20 \mathrm{~min}$ later waiting for the tank fluid to settle, using a calibrated microscale conductivity probe [26] that was mounted on a vertical, $60 \mathrm{~cm}$ long, linear positioning device, the accuracy of which was $0.1 \mathrm{~mm}$. Calibration of the conductivity probe was performed before each experiment using samples of salt water, the density of which was measured with a hydrometer of $2 \%$ accuracy. The conductivity probe was lowered abruptly, while the density and position were recorded simultaneously at a rate of $200 \mathrm{~Hz}$ with a 12 bit data acquisition card and Labview ${ }^{\circledR}$ software. From the density profile (a typical one is shown in Figure 2), the density gradient $d \rho / d z$ was evaluated and the buoyancy frequency $N$ was computed. The jet plenum was placed at the top of the stratification tank pointing downward. The nozzle elevation was located at least $15 \mathrm{~cm}$ below the free surface, to ensure that the density gradient was linear throughout the whole depth where the jet flow developed. For positively buoyant jets at nozzle elevation, the jet fluid was heavier than the ambient, while, for negatively buoyant ones, the jet fluid was lighter than the ambient.

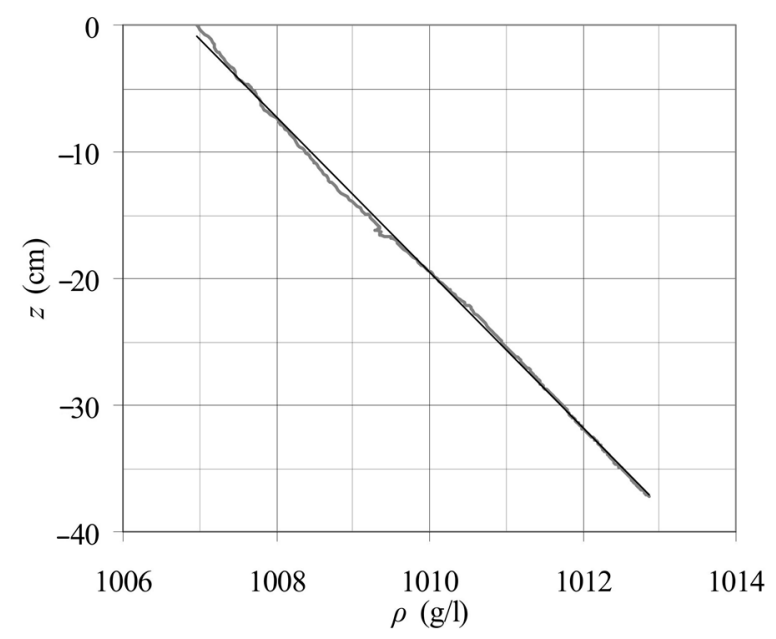

Figure 2. Density profile in the stratified tank up to $37.5 \mathrm{~cm}$ deeper than nozzle elevation (Exp-14). The thick line is the measured density, while the darker line is the least square linear approximation $\rho(z)=1006.8+0.163 z(z$ in $\mathrm{cm})$.

The jet water supply was through a constant head tank with an overflow, positioned $2 \mathrm{~m}$ above the free surface of the dispersion tank. It was filled with water of known density from a supply tank on the laboratory floor, via a submersible pump at flow rates higher than that of the jet, in order to ensure overflow. The jet flow rate was measured via a calibrated rotameter in the range $7-55 \mathrm{~cm}^{3} / \mathrm{s}$ with $2.5 \%$ accuracy. All experiments were planned according to the dimensional analysis discussed earlier. Experiments were performed in the regime $0.10<M N / B<1000$. The buoyancy frequency parameter $N^{2}$ varied from 0.058 to $0.16 \mathrm{~s}^{-2}$, the Reynolds number varied between 1870 and 8710 (the 
transition to turbulence occurred within five jet diameters from the nozzle, [24,27]), and the initial jet Richardson number varied between 0.003 and 0.406 .

The experiments were video-taped at $25 \mathrm{fps}$ with a three-CCD (charge-coupled device) camera, positioned $4 \mathrm{~m}$ far from the dispersion tank. The terminal rise height and spreading elevation were evaluated from the time series of the movie frames obtained, using Autocad ${ }^{\circledR}$ software and the two grids in the front and back transparent Lucite panels of the dispersion tank. The THR fluctuated around an average value, while the $\mathrm{SH}$ did not vary essentially throughout the experiment. Approximately 60 frames (an example is shown in Figure 3) sampled every $1 \mathrm{~s}$ were used to evaluate an average of THR and $\mathrm{SH}$, before the laterally expanding "wastefield" reached the tank walls. Initial and measured flow parameters in buoyant jets and fountains are shown in Table 3.

Table 3. Initial flow parameters and measured terminal height of the rise (THR) and spreading height (SH) from positively buoyant jet and fountain experiments [28].

\begin{tabular}{|c|c|c|c|c|c|c|c|c|c|}
\hline Run & $D$ & $Q$ & $\rho_{a}$ & $\rho_{o}$ & $N^{2}$ & $\operatorname{Re}$ & $R_{o}$ & $Z$ & $Z_{S}$ \\
\hline & $(\mathrm{cm})$ & $\left(\mathrm{cm}^{3} / \mathrm{s}\right)$ & $\left(\mathrm{gr} / \mathrm{cm}^{3}\right)$ & $\left(\mathrm{gr} / \mathrm{cm}^{3}\right)$ & $\left(s^{-2}\right)$ & & & $(\mathrm{cm})$ & $(\mathrm{cm})$ \\
\hline \multicolumn{10}{|c|}{ Positively buoyant jets } \\
\hline Exp-1 & 1.00 & 51.26 & 1.0073 & 1.0092 & 0.1303 & 7120 & 0.020 & 47.3 & 24.2 \\
\hline Exp-3 & 1.00 & 30.25 & 1.0066 & 1.0066 & 0.1350 & 4304 & 0.003 & 33.9 & 17.7 \\
\hline Exp-4 & 1.00 & 21.25 & 1.0069 & 1.0100 & 0.1302 & 3023 & 0.061 & 33.3 & 18.8 \\
\hline Exp-5 & 0.50 & 15.24 & 1.0057 & 1.0062 & 0.1541 & 4338 & 0.005 & 33.3 & 17.4 \\
\hline Exp-10 & 1.50 & 25.75 & 1.0083 & 1.0140 & 0.1074 & 2055 & 0.185 & 33.7 & 20.7 \\
\hline Exp-14 & 0.75 & 27.25 & 1.0070 & 1.0091 & 0.1584 & 4240 & 0.019 & 37.8 & 20.8 \\
\hline Exp-15 & 0.50 & 28.75 & 1.0075 & 1.0100 & 0.1276 & 7238 & 0.007 & 47.8 & 25.1 \\
\hline Exp-16 & 0.50 & 28.75 & 1.0073 & 1.0087 & 0.1269 & 6711 & 0.005 & 48.2 & 27.7 \\
\hline Exp-20 & 1.50 & 21.25 & 1.0045 & 1.0142 & 0.1454 & 2063 & 0.294 & 36.0 & 23.9 \\
\hline Exp-21 & 1.50 & 19.75 & 1.0031 & 1.0150 & 0.0809 & 1918 & 0.350 & 48.6 & 31.4 \\
\hline Exp-22 & 1.50 & 19.75 & 1.0028 & 1.0188 & 0.0705 & 1873 & 0.405 & 55.1 & 36.6 \\
\hline Exp-23 & 1.00 & 24.25 & 1.0032 & 1.0101 & 0.0745 & 3450 & 0.079 & 51.5 & 33.0 \\
\hline Exp-24 & 1.00 & 24.25 & 1.0070 & 1.0100 & 0.1505 & 3450 & 0.052 & 35.1 & 20.7 \\
\hline Exp-25 & 1.50 & 28.75 & 1.0076 & 1.0119 & 0.1520 & 2727 & 0.145 & 35.2 & 21.5 \\
\hline Exp-26 & 1.00 & 33.25 & 1.0059 & 1.0095 & 0.1176 & 4731 & 0.042 & 38.2 & 22.2 \\
\hline Exp-27 & 1.00 & 25.75 & 1.0065 & 1.0084 & 0.1473 & 3406 & 0.039 & 32.8 & 18.7 \\
\hline Exp-28 & 1.50 & 27.25 & 1.0063 & 1.0151 & 0.1196 & 2403 & 0.218 & 34.4 & 22.0 \\
\hline Exp-29 & 1.00 & 36.25 & 1.0049 & 1.0060 & 0.1545 & 4679 & 0.021 & 37.3 & 19.4 \\
\hline \multicolumn{10}{|c|}{ Fountains } \\
\hline Exp-2 & 1.00 & 36.25 & 1.0066 & 1.0060 & 0.1492 & 5036 & 0.015 & 38.9 & 20.7 \\
\hline Exp-6 & 0.50 & 21.25 & 1.0071 & 1.0032 & 0.0978 & 6046 & 0.012 & 43.3 & 24.8 \\
\hline Exp-7 & 0.50 & 30.25 & 1.0065 & 0.9969 & 0.1226 & 8710 & 0.013 & 47.6 & 24.8 \\
\hline Exp-8 & 0.75 & 30.25 & 1.0081 & 0.9969 & 0.0584 & 5807 & 0.040 & 34.0 & 10.0 \\
\hline Exp-9 & 1.00 & 36.25 & 1.0089 & 0.9986 & 0.1604 & 4340 & 0.065 & 28.4 & 9.8 \\
\hline Exp-11 & 1.00 & 36.25 & 1.0074 & 1.0054 & 0.1377 & 4340 & 0.028 & 34.3 & 16.7 \\
\hline Exp-12 & 0.75 & 28.15 & 1.0095 & 0.9986 & 0.1634 & 4493 & 0.042 & 28.5 & 12.5 \\
\hline Exp-13 & 0.50 & 27.25 & 1.0098 & 0.9988 & 0.1352 & 6361 & 0.016 & 41.4 & 20.0 \\
\hline Exp-17 & 1.00 & 27.25 & 1.0105 & 0.9988 & 0.1297 & 3180 & 0.092 & 19.4 & 0.3 \\
\hline Exp-18 & 1.00 & 26.65 & 1.0098 & 1.0015 & 0.1565 & 3526 & 0.079 & 22.3 & 4.0 \\
\hline Exp-19 & 1.00 & 21.25 & 1.0058 & 0.9975 & 0.1662 & 2881 & 0.099 & 17.9 & 1.0 \\
\hline Exp-30 & 1.00 & 30.25 & 1.0049 & 0.9978 & 0.1041 & 4002 & 0.065 & 25.3 & 7.6 \\
\hline
\end{tabular}




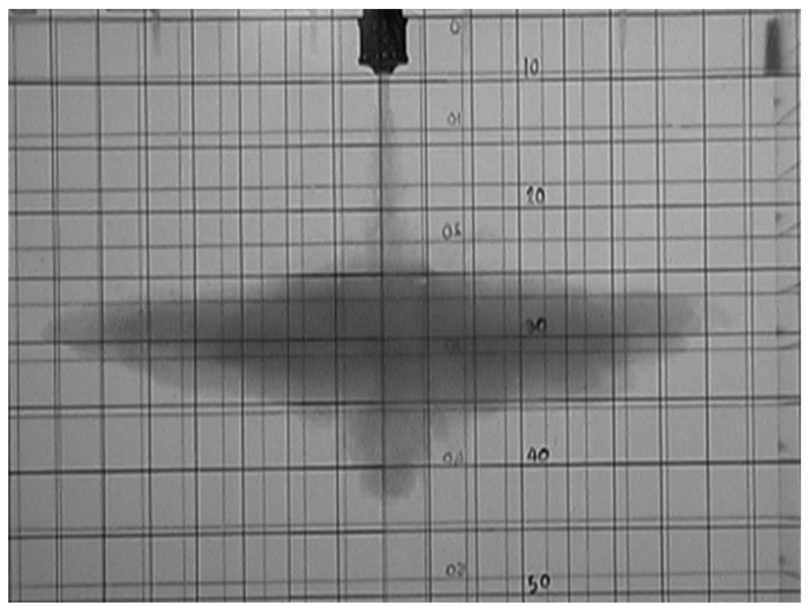

Figure 3. Typical image extracted from the videotape of an experiment of a positively buoyant jet in a linearly density-stratified ambient. Note the double grid in the front and rear Lucite panels of the dispersion tank. The jet plenum edge with nozzle is shown at the top of the photo.

Note that $N$ was computed as an "average over depth" least-square line from density profiles such as in Figure 2. This means that deviations from the "linear density" due to possible flow rate changes of the pump supplying the surface spreaders would produce local density gradients that affect both THR and SH; hence, repeatability of the experiment was impossible. Therefore, our experiments were planned and executed by varying only the dimensionless parameter $M N / B$.

The equations of motion of the mean flow in round vertical turbulent buoyant jets that discharge in a density-stratified fluid with buoyancy frequency $N$, assuming top-hat distributions for the time-averaged velocity and density excess or deficiency, are written [4] as follows:

$$
\frac{d \mu}{d z}=2 \sqrt{\pi} \alpha m^{1 / 2}, \frac{d m}{d z}=\frac{\mu \beta}{m}, \frac{\mathrm{d} \beta}{\mathrm{d} z}=-N^{2} \mu,
$$

where $\mu, m$, and $\beta$ are the local volume, specific momentum, and buoyancy fluxes, and $\alpha$ is the local entrainment coefficient. The initial conditions at the jet origin $z_{0}$ are

$$
\mu\left(z_{o}\right)=Q=\frac{\pi D^{2}}{4} W, m\left(z_{0}\right)=M=\frac{\pi D^{2}}{4} W^{2}, \beta\left(z_{o}\right)=B=\frac{\rho_{a}-\rho_{o}}{\rho_{o}} g Q .
$$

An estimate of the virtual origin distance $z_{0}$ from the nozzle can be obtained from the theory by List and Imberger [29]. In a buoyant jet, the ratio $C_{p}=\mu / z \mathrm{~m}^{1 / 2}$ is defined to be the constant jet width parameter [30] found to be equal to 0.27. Substituting the local volume and momentum fluxes in the equation above with the initial values, the jet virtual origin can be estimated as $z_{o}=Q /\left(C_{p} M^{1 / 2}\right)=3.28 D$. The system of Equation (14) can be integrated starting at $z_{0}$ with the initial conditions in Equation (15).

\section{Results}

\subsection{Positively Buoyant Jet Experiments}

The terminal height of rise and spreading height normalized with $L_{j}$ are plotted in Figure $4 \mathrm{a}, \mathrm{b}$, respectively, versus the dimensionless parameter $M N / B$. For large values of $M N / B$, i.e., for momentum-driven flows initially, both normalized THR $Z / L_{j}$ and $\mathrm{SH} Z_{S} / L_{j}$ take constant values around $3.58 \pm 0.12$ and $1.94 \pm 0.11$, respectively. These results are congruent with earlier experiments [12,13], while the data spread of $Z_{S} / L_{j}$ is lower if compared to that of the data by [13]. When the dimensionless parameter $M N / B$ is small, i.e., the flow is initially buoyancy-driven, the normalized THR $Z / L_{p}$ and SH $Z_{S} / L_{p}$ are proportional to $(M N / B)^{-1 / 4}$ as predicted from dimensional analysis. The normalized THR 
and $\mathrm{SH}$ take the values $\mathrm{Z} / \mathrm{L}_{p}=4.52 \pm 0.34$ and $\mathrm{SH} Z_{S} / L_{p}=2.95 \pm 0.34$, respectively, in agreement with results reported by the latter authors.

(a)

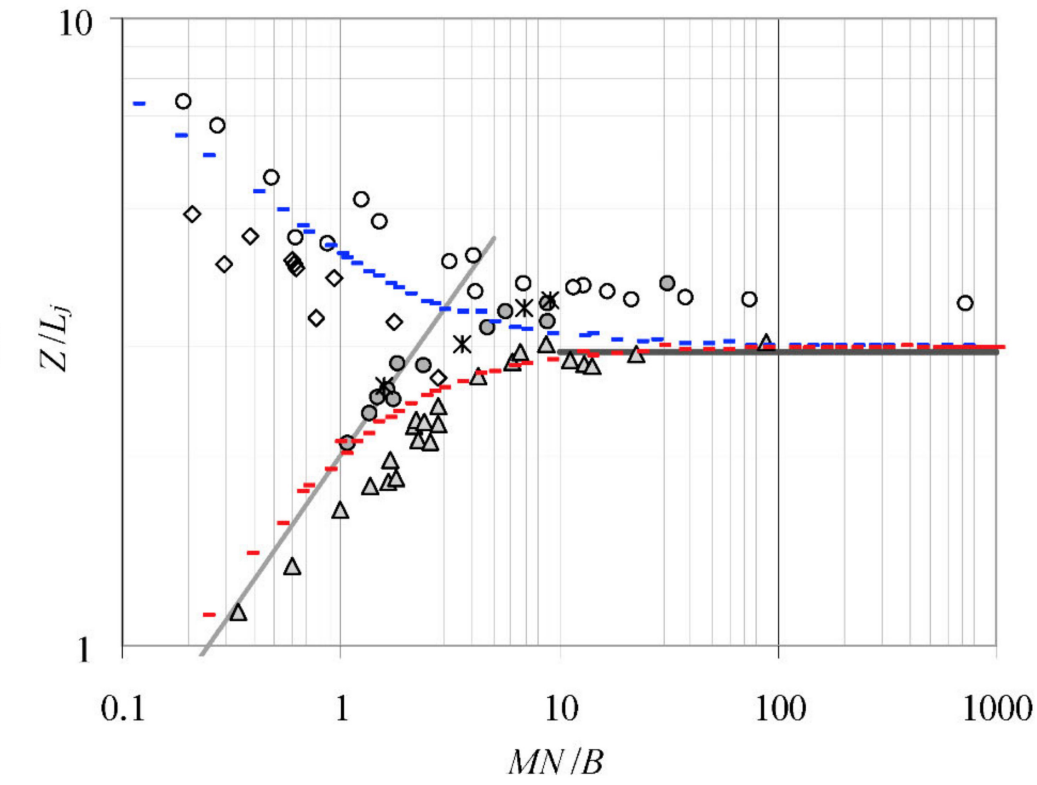

o Present $\mathrm{B}>0$

o Present $\mathrm{B}<0$

* Pap. et al. [12]

$\Delta \quad B \& K[14] \mathrm{B}<0$ $-B \& K[14] \mathrm{B}=0$ $-\mathrm{z} / \mathrm{M}=2$

$\diamond$ Zhang etal. [16]

- Calcs B>0

- Calcs $\mathrm{B}<0$

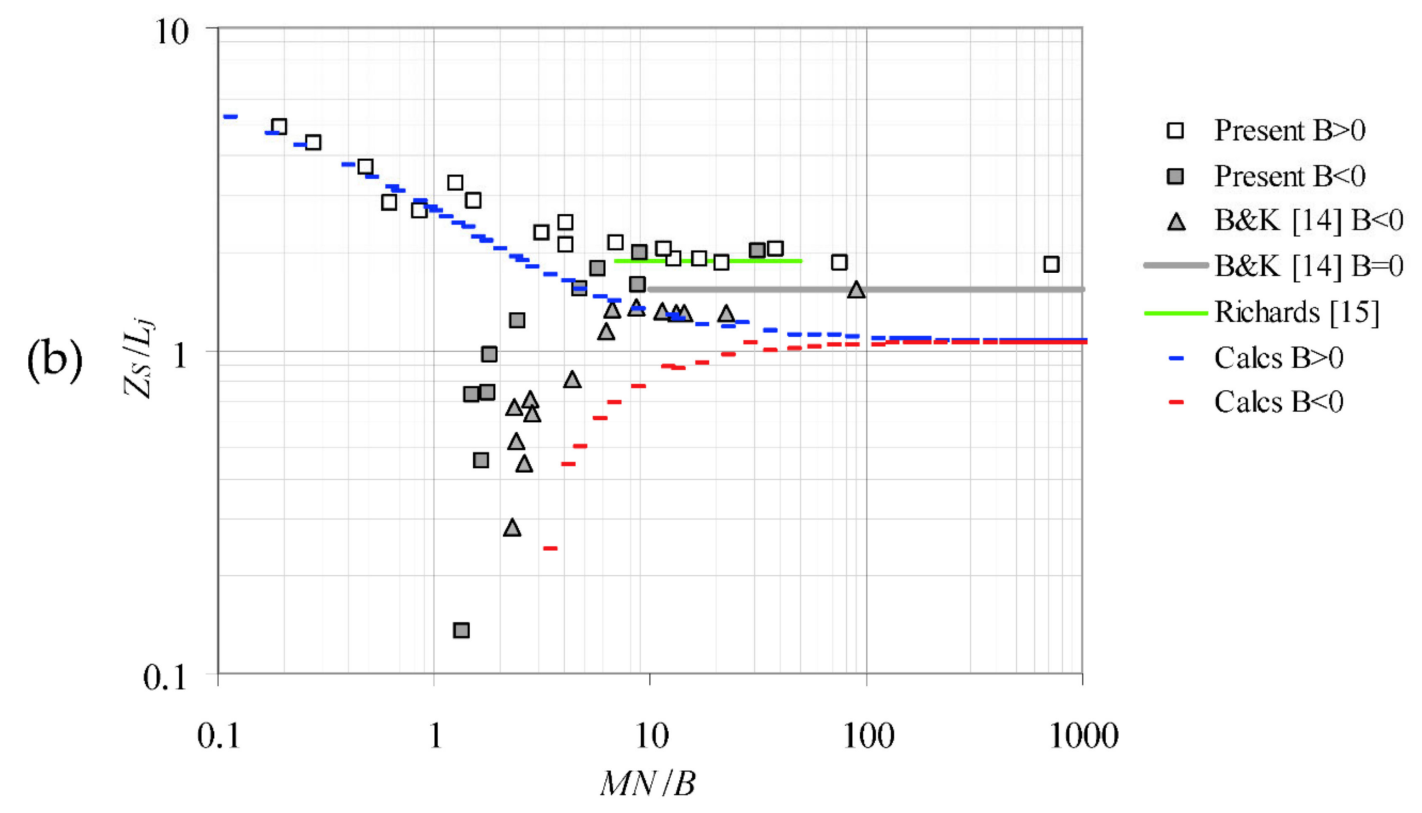

Figure 4. (a) Normalized terminal rise height $Z / L_{j}$ and (b) spreading elevation $Z_{S} / L_{j}$ (bottom) versus $M N / B$.

\subsection{Negatively Buoyant Jet (Fountain) Experiments}

The terminal height of rise and spreading height normalized with $L_{j}$ are also plotted in Figure $4 a, b$, respectively, versus $M N / B$. For large values of $M N / B$, i.e., for initially momentum-driven flows, both THR and SH take asymptotically constant values $Z / L_{j} \approx 3.60$ and $Z_{S} / L_{j} \approx 2.0$ as in buoyant jets. When $M N / B$ is small, i.e., the flow is initially buoyancy-driven, $Z / L_{j} \approx 2(M N / B)^{1 / 2}$, while $Z_{S} / L_{j} \rightarrow-\infty$. In fact, from Figure $4 \mathrm{~b}$, the present data indicate that $Z_{S} / L_{j} \rightarrow 0$ when $M N / B \rightarrow 1$. Our negatively buoyant jet data are limited to $M N / B>1$ because, at lower values, the spreading elevation coincides with the receptor boundary that is located upstream from the nozzle at the top layers of the dispersion tank. 


\subsection{Numerical Results: THR and SH, Average Dilution}

The system of Equation (14) with initial conditions in Equation (15) is an initial value problem. The solution proposed is similar to those in $[10,14]$. Nevertheless, there are differences regarding the variable entrainment coefficient used in the present investigation and the virtual origin. In our computations, we made the assumption that the density gradient in the spreading (waste) field does not vary significantly if compared to the original one. The system of entrainment equations is an initial value problem and was solved using a fourth-order Runge-Kutta routine, starting from the jet virtual origin at elevation $z_{0}$. The entrainment coefficient at distance $z$ from the source was computed as a function of the local Richardson number $\operatorname{Ri}(z)=\mu(z) \beta(z)^{1 / 2} / m(z)^{5 / 4}$ (see Appendix A) from the equation below.

$$
\alpha=\frac{C_{p}}{2 \sqrt{\pi}}\left(1+\frac{1}{2} \frac{R i^{2}(z)}{C_{p}}\right) .
$$

In positively buoyant jets $(B \geq 0)$, the jet entrainment coefficient varies from $\alpha_{j}=0.072$ to $a_{\mathrm{p}}=$ 0.119 (considering a corrected $C_{p}=0.254$ and $z_{\mathrm{o}}=3.49 \mathrm{D}$ ), while, when the buoyancy reverses, $R i^{2}(z)$ is negative; therefore, $a<0.072$. The spreading height can be roughly computed as

$$
N^{2}=-\frac{g}{\rho_{o}} \frac{\overline{\Delta \rho}}{\Delta z} \Rightarrow \Delta z=Z_{s}-Z=-\frac{g}{\rho_{o}} \frac{\overline{\Delta \rho}}{N^{2}}=\frac{\beta(Z)}{N^{2} \mu(Z)}
$$

assuming no further mixing during the descending flow from THR to SH [19], where $\Delta \rho, \mu(Z)$ and $\beta(Z)$ are the average density difference, the specific mass, and buoyancy fluxes, respectively, at the THR.

Note that the findings from computations using top-hat, time-averaged velocity and density difference profiles are not any different from those using Gaussian distributions.

The results from computations regarding the normalized THR and SH are plotted in Figure 4 for both buoyant jets and fountains. For jet-like flows and fountains $(M N / B>>1)$, the numerical predictions are quite lower than our measurements, since the computed $Z / L_{j}=3.0$ and $Z_{S} / L_{j}=1.07$ are lower than measured values of 3.50 and 2.0, respectively. For initially buoyancy-driven jets $(M N / B<1)$, the numerical predictions give $Z / L_{p}=4.25$ and $Z_{S} / L_{p}=3.1$. The normalized THR is near the measured one (4.50), while the normalized SH is nearly the same as the predicted SH.

Measurements regarding the dilution of buoyant jets in a linearly stratified uniform ambient were reported by Wong and Wright [10], who measured the dilution of fluorescein dye in the spreading layer. They reported the normalized minimum dilution (that corresponds to maximum time-averaged concentration $\left.c_{m}\right) S_{m} Q /\left(B^{3 / 4} / N^{5 / 4}\right)$ versus $M N / B$. If the initial dye concentration of a jet is $C_{o}$, then $S_{m}=C_{o} / c_{m}$. From tracer conservation equation $Q C_{o}=\mu(z) c$ (where $c$ is the average dilution), the dimensionless minimum dilution can be expressed as

$$
\frac{Q S_{m} N^{1 / 2}}{M^{3 / 4}}=\frac{Q\left(C_{o} / c_{m}\right) N^{1 / 2}}{M^{3 / 4}}=\frac{\left(c / c_{m}\right) \mu(z) N^{5 / 4}}{B^{3 / 4}}
$$

where the ratio $c / c_{m}<1$, as the average over a cross-section dye concentration, is only a portion of the maximum time-averaged concentration.

In Figure 5, the normalized minimum dilution from experiments in [10] is plotted along with the computed normalized average dilution $\mu N^{1 / 2} / M^{3 / 4}$. From this figure, one may note several findings. In plumes $(M N / B<1)$, the normalized average dilution takes the value $d_{p}=0.87$, which is near the 0.84 suggested in [4] and higher than 0.80 , an average value of the minimum dilution proposed by [10], as expected. From Equation (16), $c_{m} / c=1.09$, a value that is different from 1.40 proposed by [4] for round plumes in uniform ambient. From experiments in [10], the vertical distribution of concentration in the spreading field seems to be uniform. Therefore, an average concentration should be near the maximum, resulting in similar values of minimum and average dilutions. In jets $(M N / B>10)$, the 
computed dimensionless average dilution is $d_{j}=0.52$, a value that is lower than the minimum dilution 0.67 measured in [4], following the trend of the normalized THR and SH in this regime.

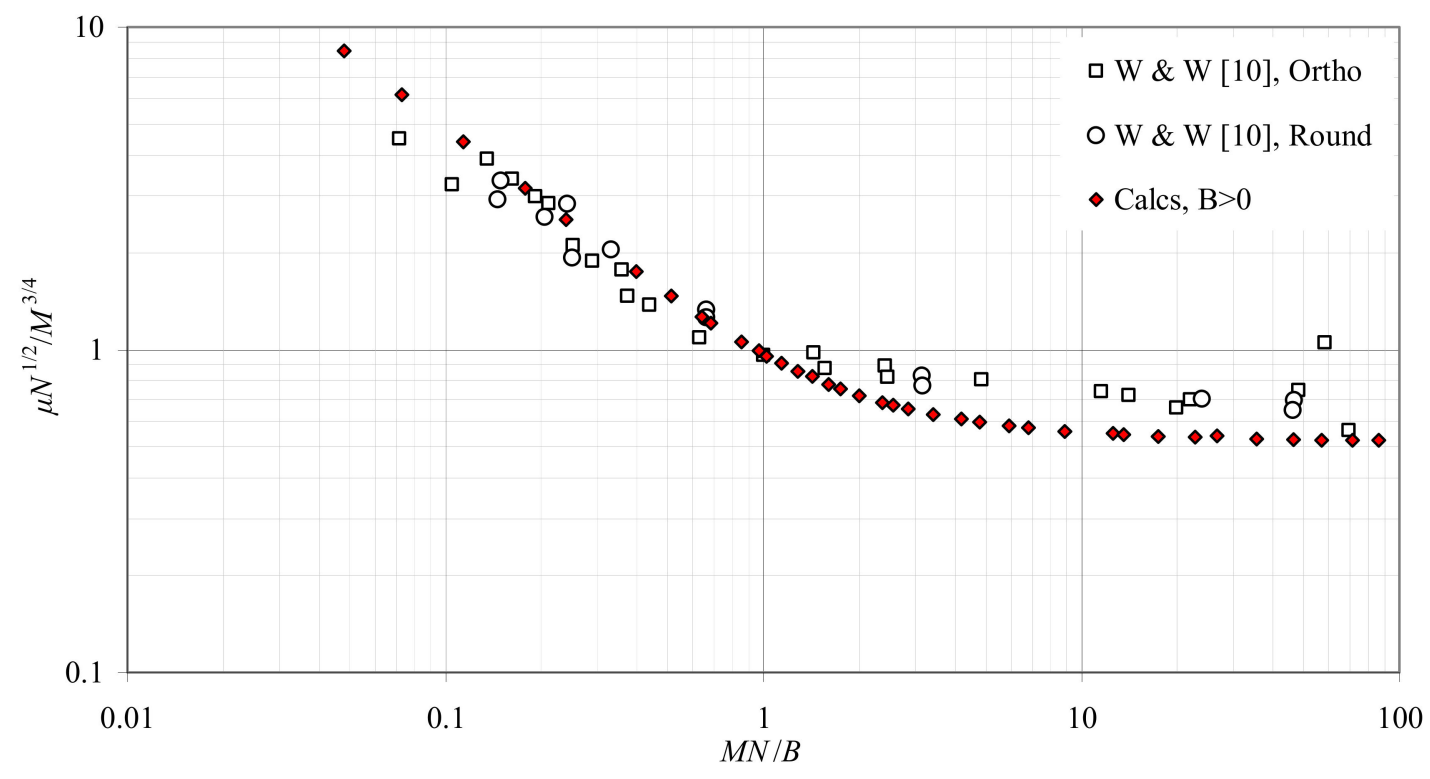

Figure 5. Normalized dilution plotted versus $M N / B$ for positively buoyant jets from measurements of Wong and Wright [10] (squares and circles) and the computation using top-hat modeling.

\section{Discussion}

From Figure 4, it is evident that positively buoyant jets and fountains converge asymptotically to the same THR $Z / L_{j} \approx 3.50$ and $S H Z_{S} / L_{j} \approx 2$ when $M N / B>10$. The results regarding THR are congruent with earlier measurements $[5,10,12,13,16]$ but higher than the 3.0 reported in [14], as shown in Table 2 . The results regarding SH are also higher than the 1.50 reported in [14,16] and lower than the 2.38 in [13], as shown in Table 2 as well. Analyzing the data in [16] using dimensional arguments from Section 2, the normalized SH elevation must be corrected to 1.89 , a value that is near the measurements of the present study.

In the same figure, one may note that the data by [14] regarding fountains in a linearly, density-stratified fluid for $M N / B>>1$ give asymptotic dimensionless constants of 2.88 for THR and 1.52 for $\mathrm{SH}$, which are also lower from those in the present investigation. There are also differences in the dimensionless THR and SH between the present measurements and those in [14] when the parameter $M N / B$ is small, the values of the latter being systematically lower than those measured in the present experiment. According to dimensional analysis presented in Section 2, as $M N / B \rightarrow 0$ when $N \rightarrow 0$ (uniform ambient density) and the jet momentum is driving the flow, the normalized THR $Z / l_{\mathrm{M}} \rightarrow C$ [21] or $Z / L_{j}=C(M N / B)^{1 / 2}$. Recent experiments [21,31] indicated that $C \approx 2$, while [32] reported a constant $C=1.70$. In Figure $4 \mathrm{a}$, the line $Z / L_{j}=2(M N / B)^{1 / 2}$ is plotted for comparison, which is closer to the present data than those reported in [14]. In the same graph, we show four points from the unpublished data of [12] that are near the present findings.

When the flow is buoyancy-driven $(B>0)$ using dimensional arguments in Section 2, analysis of the present data in Table 3 shows that the normalized THR $Z / L_{p} \approx 4.50$ and SH $Z_{S} / L_{p} \approx 3.0$ when $M N / B<1$. The results regarding the normalized THR are congruent to those in $[10,12]$ but higher than those in $[1,13,16]$. The results regarding the normalized SH are very close to 2.80 [15] and 3.0 [13], thus confirming their validity.

Numerical predictions using the entrainment coefficient derived from mass and momentum conservation equations led to accurate predictions regarding the spreading elevation and average dilution if compared to our measurements, as seen in Figures 4 and 5, when the flow is buoyancy-driven 
$(M N / B<1)$. In this regime the predicted THR is a little lower than our measurements. In jet-like flow and fountain regimes $(M N / B>>1)$, however, the predictions are lower than our measurements (3.06 vs. 3.50) for THR and much lower (1.06 vs. 2 ) for $\mathrm{SH}$. The normalized average dilution in this regime turned out to be lower than the measured minimum dilution [10], a result that is against the physics of flow.

Nevertheless, in this regime, the results from integral models employed by others provided even lower values of normalized parameters. For example, the computed normalized THR in plumes [10] was 3.55 vs. measured 4.45 and that in jets was 3.06 vs. 3.60. The computed normalized dilutions in [10] were 0.42 vs. measured 0.68 in jets and 0.70 vs. measured 0.80 in plumes, results that are lower than minimum dilutions measured and contradictory to physics. Jirka [33] computed the normalized THR and $\mathrm{SH}$ using CorJet software and found values of 3.30 and 1.50, respectively, values that are lower than those measured in jets. To estimate THR, in addition to the elevation $Z$ of the THR where momentum flux vanishes, $\sqrt{ } 2 b$ (where $b$ is the local jet width) was added in [34]; thus, $(Z+\sqrt{ } 2 b) / L_{j}=3.30$.

\section{Conclusions}

Turbulent vertical buoyant jets and fountains in a linearly density-stratified fluid were investigated experimentally and numerically. Data from earlier investigations were collected, analyzed, and put together according to dimensional analysis, leading to asymptotic constants. A positively buoyant jet $(B \geq 0)$ is momentum-driven if the dimensionless parameter $M N / B>10$. In this regime, the normalized terminal height of rise (THR) $Z / L_{j}$ and mean spreading elevation $(\mathrm{SH}) Z_{S} / L_{j}$ take constant values around 3.5 and 2 , respectively. The flow is buoyancy-driven if $M N / B<1$, and, in this regime, the normalized THR $Z / L_{p}$ and $S H Z_{S} / L_{p}$ take values around 4.50 and 3 , respectively. The regime $1<M N / B<10$ is considered to be the transition from plume-like to jet-like flows, where the initial specific momentum and buoyancy fluxes $M$ and $B$ are of equal importance for the development of the flow.

A negatively buoyant jet $(B<0)$ or fountain is momentum-driven if $M N / B>10$. The normalized THR $Z / L_{j}$ and $\mathrm{SH} Z_{S} / L_{j}$ take asymptotically the same values as momentum-driven positively buoyant flows, which are around 3.50 and 2 , respectively. For $M N / B<10$, the flow is buoyancy-driven, and the normalized THR $Z / l_{M}$ takes an asymptotic value around 2 as $M N / B \rightarrow 1$, which is compatible with dimensional analysis and experiments of vertical fountains in a uniform ambient [21,31], while the $\mathrm{SH}$ is that of the nozzle elevation $\left(Z_{S}=0\right)$ as $M N / B \rightarrow 1.5$.

Both THR and $\mathrm{SH}$ were obtained numerically from the equations of motion, using variable entrainment coefficient $\alpha$ that is a function of the local Richardson number of the flow. In buoyancy $=$ driven flows $(M N / B<1)$, the computed THR and SH were found to be congruent to the measured ones. In momentum-driven flows $(M N / B>10)$ and fountains $(B<0)$, both THR and SH obtained numerically were not compatible with measurements.

The average dilution obtained numerically in buoyancy-driven jets $(M N / B<1)$ was in accordance with earlier dilution measurements [10]. However, the computed average dilution in the jet-like flow regime $(M N / B>10)$ was far from the measured minimum dilution [10], although the experimental data showed substantial scatter. We believe that velocity and concentration measurements using laser light-based tomography of the flow have to be made in order to understand the physics of dispersion of buoyant jets in a density-stratified ambient.

The entrainment coefficient function that was derived from the equations of motion of vertical buoyant jets in a uniform ambient seems to work quite well, especially in regimes where the discharges are plume-like initially or if $M N / B<1$. Since it is related to the squared local Richardson number of the flow, when the buoyancy acts against the movement, the computed entrainment coefficient is lower than that measured in jets, a result that were previously thoroughly discussed $[18,19,34]$.

Author Contributions: Conceptualization, P.N.P.; methodology, P.N.P. and G.C.S.; software, P.N.P.; validation, G.C.S.; investigation, P.N.P. and G.C.S.; data curation, G.C.S.; writing-review and editing, P.N.P.; supervision, P.N.P. All authors have read and agreed to the published version of the manuscript.

Funding: This research received no external funding. 
Acknowledgments: Part of this work was presented at the Sixth International Symposium of Environmental Hydraulics, 23-25 June 2010, Athens, Greece. The assistance of Elias Pappas and Demetris Karaberopoulos is gratefully appreciated.

Conflicts of Interest: The authors declare no conflict of interest.

\section{Appendix A. The Entrainment of Round Vertical Turbulent Buoyant Jets Re-Revisited}

\section{Appendix A.1. Introduction}

The use of the entrainment coefficient is necessary for computations of buoyant jets using one-dimensional modeling and employing the set of entrainment equations. List, in [4], proposed two equations, a linear one and an empirical exponential, where the asymptotic values of jet and plume entrainment coefficients $a_{j}$ and $a_{p}$, respectively, are used along with the constant plume Richardson number $R i_{p}$.

$$
\alpha=\alpha_{j}-\left(\alpha_{j}-\alpha_{p}\right)\left(\frac{R i(z)}{R i_{p}}\right)^{2} \text { and } \alpha=\alpha_{j} \exp \left[\left(\frac{R i(z)}{R i_{p}}\right)^{2} \ln \left(\frac{\alpha_{p}}{\alpha_{j}}\right)\right] .
$$

The equation to the left is attributed to a derivation where the equation of energy was employed [35], while the equation to the right is empirical. Both produce the same asymptotic values for pure jets and plumes. Apparently, to employ these relationships, one must know a priori $a_{j}, a_{p}$ and $R i_{p}$. The entrainment coefficients for Gaussian distributions of velocity and density difference as suggested in [4] are $a_{j}=0.0535 \pm 0.0025(0.075), a_{j}=0.0833 \pm 0.0042(0.118)$, and $R i_{p}=0.557$, the values in parentheses corresponding to top-hat distributions of velocity and density difference. In the next section, we derive an equation for the local entrainment coefficient, using the entrainment equations of a vertical, buoyant, axisymmetric jet.

When computing fountains or jets of reverse (with respect to the motion) buoyancy, it was shown $[18,34]$ that the entrainment coefficient is lower than $a_{j}$. This assumption was also made by [19], where the jet entrainment coefficient was reduced in order to attain numerically the values of measurements of parameters such as the terminal rise height of buoyant jets and fountains in linearly, density-stratified and in uniform ambient, respectively.

\section{Appendix A.2. Derivation of Entrainment Coefficient in Round Buoyant Jets}

The entrainment equations of motion of a fully developed, axisymmetric, Boussinesq, turbulent buoyant jet in a uniform and motionless fluid of greater density, using top-hat velocity and density deficit profiles, are written as follows [1,4]:

$$
\frac{d \mu}{d z}=2 \sqrt{\pi} \alpha m^{1 / 2}, \frac{d m}{d z}=\frac{\mu \beta}{m}, \frac{d \beta}{d z}=0,
$$

where $\alpha$ is the local entrainment coefficient, $\mu, m$, and $\beta$ are the local specific (per unit mass) mass, momentum, and buoyancy fluxes, respectively, written in terms of the time-averaged streamwise top-hat velocity $w$, the jet width $b$, and the time-averaged density difference between jet and ambient fluid $\Delta \rho$ as

$$
\mu(z)=\pi b^{2} w, m(z)=\pi b^{2} w^{2}, \beta(z)=\pi \frac{\Delta \rho}{\rho_{o}} g b^{2} w,
$$

and $\rho_{o}$ is a reference density, such as the jet density at the source. In a motionless uniform ambient, the buoyancy flux is usually conserved $(\beta=B=$ constant); thus, the momentum equation can be written as

$$
\frac{d m}{d z}=\frac{\mu \beta}{m}=\frac{\beta}{m^{1 / 2}} \frac{\mu}{m^{1 / 2}} \Leftrightarrow m^{1 / 2} \frac{d m}{d z}=\beta C_{p} z,
$$


where $C_{p}$ is the constant buoyant jet width parameter [29],

$$
C_{p}=\frac{\mu}{z m^{1 / 2}}
$$

evaluated from the measurements [30] shown in Figure A1.

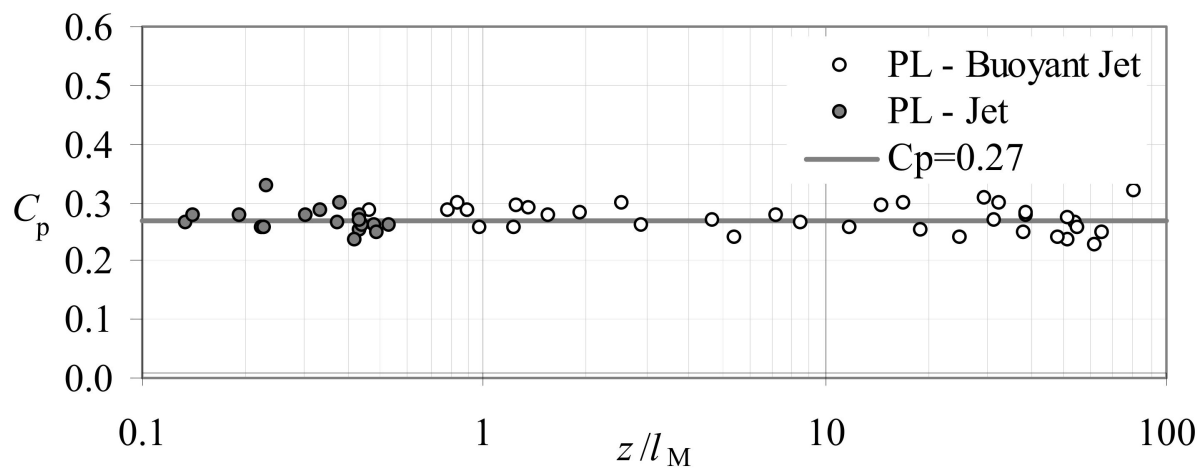

Figure A1. Buoyant jet width parameter plotted against the dimensionless elevation (data points from Papanicolaou and List [30]).

Hence, the solution of the ordinary differential Equation (A4) is

$$
\frac{d m^{3 / 2}}{d z}=\frac{3}{2} \beta C_{p} z \Rightarrow m^{3 / 2}=\frac{3}{4} \beta C_{p} z^{2}+C,
$$

where $C$ is the integration constant. At $z=0, m=M$; therefore, $C=M^{3 / 2}$, and the normalized local specific momentum flux $m(z) / M$ as a function of the normalized distance $z / l_{\mathrm{M}}$ from the source is

$$
\frac{m}{M}=\left[1+\frac{3}{4} C_{p}\left(\frac{z}{l_{M}}\right)^{2}\right]^{2 / 3}, l_{M}=\frac{M^{3 / 4}}{B^{1 / 2}} .
$$

From the momentum equation, one may obtain the local volume flux ( $\beta=$ constant) as

$$
\frac{d m}{d z}=\frac{\mu \beta}{m} \Leftrightarrow \mu=\frac{1}{\beta} m \frac{d m}{d z}=\frac{1}{2 \beta} \frac{d m^{2}}{d z} .
$$

After some algebra, Equations (A6) and (A7) give

$$
\frac{\mu}{Q} R i_{o}=\frac{\mu \beta^{1 / 2}}{M^{5 / 4}}=C_{p}\left(\frac{z}{l_{M}}\right)\left[1+\frac{3}{4} C_{p}\left(\frac{z}{l_{M}}\right)^{2}\right]^{1 / 3}, R i_{o}=\frac{Q B^{1 / 2}}{M^{5 / 4}} .
$$

Equation (A8) is a measure of a jet bulk (average) dilution $S(z)=\mu(z) / Q$ at distance $z$ from the source. Equations (A6) and (A8) for the computation of the momentum and buoyancy fluxes, respectively, are congruent with the experiments [30], as shown in [36]. Substituting the momentum and volume fluxes from Equations (A6) and (A8) into the continuity equation, one can obtain the buoyant jet entrainment coefficient as follows:

$$
\alpha=\frac{1}{2 \sqrt{\pi m}} \frac{d \mu}{d z}=\frac{C_{p}}{2 \sqrt{\pi}}\left\{1+\frac{1}{2} C_{p}\left(\frac{z}{l_{M}}\right)^{2}\left[1+\frac{3}{4} C_{p}\left(\frac{z}{l_{M}}\right)^{2}\right]^{-1}\right\} .
$$


The local Richardson number is obtained from $\operatorname{Ri}(z)=\mu \beta^{1 / 2} / m^{5 / 4}$ upon substitution from Equations (A6) and (A8); thus,

$$
R i(z)=C_{p}\left(\frac{z}{l_{M}}\right)\left[1+\frac{3}{4} C_{p}\left(\frac{z}{l_{M}}\right)^{2}\right]^{-1 / 2} .
$$

Therefore, from Equations (A9) and (A10), the entrainment coefficient in terms of the local Richardson number is written as

$$
\alpha=\frac{C_{p}}{2 \sqrt{\pi}}\left(1+\frac{1}{2} \frac{R i^{2}(z)}{C_{p}}\right) ; R i^{2}(z)=\frac{\mu^{2} \beta}{m^{5 / 2}} .
$$

\section{Appendix A.3. Verification of Entrainment Coefficient in Round Buoyant Jets}

Equations (A6) and (A8) were plotted [36] for comparison with data [30] obtained in dimensionless form. The normalized computed volume flux was congruent with measurements, while the normalized computed momentum flux was somewhat higher from measurements. Using the time-averaged streamwise velocity profile [30] in computing of the local momentum flux, [36,37] indicated that turbulent intensity may contribute as much as $14 \%$ and $11 \%$, respectively, of the momentum from time-averaged velocity to the flow. Increasing the momentum flux by an average of $12.5 \%$, from Figure A1, the adjusted $C_{p}$ would read $C_{p}^{\prime}=0.27 / 1.13^{1 / 2}=0.254$. Hence, the asymptotic values of flow parameters for vertical axisymmetric pure jets and plumes derived from the analytical solution in the previous section are as follows:

(i) Momentum flux: When $z / l_{M}<<1$ (jet-like flow), Equation (A6) leads to $m=M$, while, when $z / l_{M}>10$ (plume-like flow), it leads to

$$
\frac{m}{M} \approx\left[\frac{3}{4} C_{p}\left(\frac{z}{l_{M}}\right)^{2}\right]^{2 / 3} \Leftrightarrow m \approx\left(\frac{3}{4} C_{p}\right)^{2 / 3} \beta^{2 / 3} z^{4 / 3}=0.331 \beta^{2 / 3} z^{4 / 3}
$$

(ii) Volume flux: Similarly, when $z / l_{M}<<1$, from Equation (A8), one may obtain

$$
\frac{\mu}{Q}=\frac{C_{p}}{R i_{o}}\left(\frac{z}{l_{M}}\right) \Leftrightarrow \frac{\mu}{Q}=\frac{C_{p} M^{5 / 4}}{Q \beta^{1 / 2}} \frac{z \beta^{1 / 2}}{M^{3 / 4}} \Rightarrow \frac{\mu}{Q}=C_{p} \frac{z}{l_{Q}}=C_{p} \sqrt{\frac{4}{\pi}} \frac{z}{D}=C_{p} \frac{z}{l_{Q}} ; l_{Q}=\sqrt{\frac{\pi D}{4}},
$$

while, when $z / l_{M}>10$, from Equation (A8) one may obtain

$$
\frac{\mu}{Q} \approx \frac{C_{p}^{4 / 3}}{R i_{o}}\left(\frac{3}{4}\right)^{1 / 3}\left(\frac{z}{l_{M}}\right)^{5 / 3} \Rightarrow \mu \approx\left(\frac{3}{4}\right)^{1 / 3} C_{p}^{4 / 3} \beta^{1 / 3} z^{5 / 3}=0.146 \beta^{1 / 3} z^{5 / 3}
$$

(iii) Richardson number: In jets $\left(z / l_{M} \rightarrow 0\right)$, from Equation (A10), $R i(z) \rightarrow C_{p} z / l_{M}$, while, in plumes, $\left(\mathrm{z} / l_{\mathrm{M}} \rightarrow \infty\right) \operatorname{Ri}(z) \rightarrow \sqrt{4 C_{p} / 3}=0.58$

(iv) Entrainment coefficient: In momentum jets $\left(l_{\mathrm{M}} \rightarrow \infty\right), \alpha_{j}=C_{p} / 2 \sqrt{\pi}=0.072$, while, in plumes $\left(\mathrm{z} / \mathrm{l}_{\mathrm{M}} \rightarrow \infty\right)$,

$$
\alpha=\frac{C_{p}}{2 \sqrt{\pi}}\left\{1+\frac{1}{2} C_{p}\left(\frac{z}{l_{M}}\right)^{2}\left[1+\frac{3}{4} C_{p}\left(\frac{z}{l_{M}}\right)^{2}\right]^{-1}\right\} \approx \frac{C_{p}}{2 \sqrt{\pi}}\left\{1+\frac{2}{3}\right\}=\frac{5}{6} \frac{C_{p}}{\sqrt{\pi}}=0.119 .
$$

The values compare well to those proposed by [4] and to those measured by [30,38], as shown in Table A1. Note that the above values are for top-hat velocity and concentration distributions and must be divided by $\sqrt{ } 2$ in order to obtain those for Gaussian distributions. 
Table A1. Comparison between measured and computed parameters in vertical jets and plumes using our analytical solution (top-hat formulation).

\begin{tabular}{lccccccc}
\hline & Jet & Plume & Jet & Plume & Jet & Plume & Plume \\
\hline$C_{p}$ & $\frac{m}{M}$ & $\frac{m}{\beta^{2 / 3} z^{4 / 3}}$ & $\frac{\mu / Q}{z / l_{Q}}$ & $\frac{\mu}{\beta^{1 / 3} z^{5 / 3}}$ & $\alpha_{j}$ & $\alpha_{p}$ & $R i_{p}$ \\
\hline 0.270 & 1 & 0.345 & 0.270 & 0.159 & 0.076 & 0.127 & 0.600 \\
0.254 & 1 & 0.331 & 0.254 & 0.146 & 0.072 & 0.119 & 0.582 \\
\hline Fischer et al. [4] & & & 0.250 & 0.150 & 0.076 & 0.118 & 0.557 \\
Papanicolaou and List [30] & & 0.290 & 0.250 & 0.140 & 0.077 & 0.124 & 0.630 \\
Wang and Law [38] & & & & & 0.074 & 0.124 & 0.584 \\
\hline
\end{tabular}

\section{Appendix A.4. Conclusions}

The analysis presented in this Appendix regards a direct derivation of the entrainment coefficient for buoyant jets using the system of entrainment equations, i.e., the mass and momentum conservation. The entrainment coefficient is a function of the jet growth parameter (jet width) only, which is near the value $0.25 z$, where $z$ is the elevation from the source. It is evaluated using the local Richardson number squared, such that its sign may be positive or negative if the flow is either positively buoyant or a fountain, respectively. This is congruent with derivations [18,34], as well as the assumption [19] that it should be reduced below the jet entrainment coefficient in flows where buoyancy has the opposite sign with respect to the direction of motion.

The local buoyant jet entrainment coefficient computed directly from the local Richardson number using Equation (A11) is analogous to the linear Equation (A1), since the entrainment coefficient is a linear function of $R i^{2}(z)$, and quite different from the exponential one. The entrainment coefficient computed from Equation (A11) is independent of the sign of buoyancy with respect to the direction of motion. If the buoyancy has opposite sign (negative) from that of the direction of motion, then $a$ is reduced and it takes positive values up to Richardson numbers greater than or equal to $-2 C_{p}$. For local Richardson numbers lower than $-2 C_{p}$, the entrainment coefficient becomes negative; therefore, it is meaningless and, in the computation of flows with negative or reversing buoyancy, should be considered zero. Equation (A11) derived here is better to be applied to flows with negative buoyancy instead of Equation (A1) on the left, since, in the latter, the asymptotic plume Richardson number of positively buoyant jets has to be employed, which does not appear in negative or reversing buoyancy. Note that, in negatively buoyant jets, the local Richardson number $R i^{2}(z)$ has a limit at $-\infty$.

\section{References}

1. Morton, B.R.; Taylor, G.I.; Turner, J.S. Turbulent gravitational convection from maintained instantaneous sources. Proc. R. Soc. Lond. 1956, A234, 1-23.

2. Turner, J.S. Jets and plumes with negative or reversing buoyancy. J. Fluid Mech. 1966, 26, 779-792. [CrossRef]

3. Abraham, G. Jets with negative buoyancy in homogeneous fluid. J. Hydraul.Res. 1967, 5, 235-248. [CrossRef]

4. Fischer, B.H.; List, J.E.; Koh, R.C.Y.; Imberger, J.; Brooks, N.H. Mixing in Inland and Coastal Waters; Academic Press, Inc.: New York, NY, USA, 1979.

5. Fan, L.-N. Turbulent Buoyant Jets into Stratified or Flowing Ambient Fluids; Technical Report, KH-R-15; WM Keck Laboratory of WM Keck Laboratory of Hydraulics \& Water Resources, California Institute of Technology: Pasadena, CA, USA, 1967.

6. Fox, D.G. Forced plumes in a stratified fluid. J. Geophys. Res. 1970, 75, 6818-6835. [CrossRef]

7. Chen, C.J.; Rodi, W. Vertical Turbulent Buoyant Jets-A Review of Experimental Data; Pergamon Press: Oxford, UK, 1980.

8. Crawford, T.V.; Leonard, A.S. Observations of buoyant plumes in calm stably stratified air. J. Appl. Meteorol. 1962, 1, 251-256. [CrossRef]

9. Briggs, G.A. Plume Rise; TID 25075; Clearinghouse of Federal Scientific and Technical Information: Springfield, VA, USA, 1969. 
10. Wong, D.R.; Wright, S.J. Submerged turbulent jets in stagnant linearly stratified fluids. J. Hydraul. Res. 1988, 26, 199-223. [CrossRef]

11. Abraham, G.; Eysink, W.D. Jets issuing into fluid with density gradient. J. Hydraul. Res. 1969, 7, 145-175. [CrossRef]

12. Papanicolaou, P.N.; Synolakis, C.E.; Hodge, D. The Maximum Height of Rise of Elliptical and Round Buoyant Jets in A Linear Density—Stratified Fluid; School of Engineering, University of Southern California: Los Angeles, CA, USA, 1990.

13. Konstantinidou, K.; Papanicolaou, P.N. Vertical round and orthogonal buoyant jets in a linear density-stratified fluid. In Proceedings of the 30th IAHR Congress, Thessaloniki, Greece, 24-29 August 2003; Theme C. Volume 1, pp. 293-300.

14. Bloomfield, L.J.; Kerr, R.C. Turbulent fountains in a stratified fluid. J. Fluid Mech. 1998, 358, 335-356. [CrossRef]

15. Richards, T.S.; Aubourg, Q.; Sutherland, B.R. Radial intrusions from turbulent plumes in uniform stratification. Phys. Fluids 2014, 26, 036602. [CrossRef]

16. Zhang, W.; He, Z.; Jiang, H. Scaling for turbulent viscosity of buoyant plumes in stratified fluids: PIV measurement with implications for submarine hydrothermal plume. Deep Sea Res. Part I 2017, 129, 89-98. [CrossRef]

17. Carazzo, G.; Kaminski, E.; Tait, S. On the rise of turbulent plumes: Quantitative effects of variable entrainment for submarine hydrothermal vents, terrestrial and extra terrestrial explosive volcanism. J. Geophys. Res. 2008, 113. [CrossRef]

18. Kaminski, E.; Tait, S.; Carazzo, G. Turbulent entrainment in jets with arbitrary buoyancy. J. Fluid Mech. 2005, 526, 361-376. [CrossRef]

19. Papanicolaou, P.N.; Papakonstantis, I.G.; Christodoulou, G.C. On the entrainment coefficient in negatively buoyant jets. J. Fluid Mech. 2008, 614, 447-470. [CrossRef]

20. Wood, I.R.; Bell, R.G.; Wilkinson, D.R. Ocean Disposal of Wastewater; World Scientific: Singapore, 1993.

21. Papanicolaou, P.N.; Kokkalis, T.J. Vertical buoyancy preserving and non-preserving fountains, in a homogeneous calm ambient. Int. J. Heat Mass Transfer 2008, 51, 4109-4120. [CrossRef]

22. Michas, S.N.; Papanicolaou, P.N. Horizontal round heated jets into calm uniform ambient. Desalination 2009, 248, 803-815. [CrossRef]

23. Oster, G.; Yamamoto, M. Density gradient techniques. Chem. Rev. 1963, 63, 257-268. [CrossRef]

24. Papanicolaou, P.N. A piston driven jet for the study of the zone of flow establishment. Exp. Fluids 1994, 17, 287-289. [CrossRef]

25. Mi, J.; Nobes, D.S.; Nathan, G.J. Influence of jet exit conditions on the passive scalar field of an axisymmetric free jet. J. Fluid Mech. 2001, 432, 91-125. [CrossRef]

26. Head, M.J. The Use of Miniature 4-Electrode Conductivity Probes for High Resolution Measurements of Turbulent Density or Temperature Variations in Salt Stratified Water Flows. Ph.D. Thesis, University of California San Diego, San Diego, CA, USA, 1983.

27. Kwon, S.J.; Seo, I.W. Reynolds number effects on the behavior of a non-buoyant round jet. Exp. Fluids 2005, 38, 801-812. [CrossRef]

28. Stamoulis, G. Vertical Round Positively and Negatively Buoyant Jets in a Linearly Density-Stratified Ambient. Diploma Thesis, University of Thessaly, Department of Civil Engineering, Volos, Greece, 2010. (In Greek).

29. List, E.J.; Imberger, J. Turbulent entrainment in buoyant jets and plumes. ASCE J. Hyraul. Div. 1973, 99, 1461-1474.

30. Papanicolaou, P.N.; List, E.J. Investigations of round vertical turbulent buoyant jets. J. Fluid Mech. 1988, 195, 341-391. [CrossRef]

31. Papakonstantis, E.G.; Christodoulou, G.C.; Papanicolaou, P.N. Inclined negatively buoyant jets 1: Geometrical characteristics. J. Hydraul. Res. 2011, 49, 3-12. [CrossRef]

32. Bloomfield, L.J.; Kerr, R.C. A theoretical model of a turbulent fountain. J. Fluid Mech. 2000, 424, $197-216$. [CrossRef]

33. Jirka, G.H. Integral model for turbulent buoyant jets in unbounded stratified flows. Part I: Single round jet. Env. Fluid Mech. 2004, 4, 1-56. [CrossRef]

34. Carazzo, G.; Kaminski, E.; Tate, S. The route to self similarity in turbulent jets and plumes. J. Fluid Mech. 2006, 547, 137-148. [CrossRef] 
35. Priestley, C.H.B.; Ball, F.K. Continuous convection from an isolated sourse of heat. Q.J.R. Met. Soc. 1955, 81, 144-157. [CrossRef]

36. Papanicolaou, P.N. Analytical solution in vertical buoyant jets. In Proceedings of the 11th HSTAM International Congress on Mechanics, Athens, Greece, 27-30 May 2016.

37. Papanicolaou, P.N. Mass and Momentum Transport in a Turbulent Buoyant Vertical Axisymmetric Jet. Ph.D. Thesis, W.M. Keck Laboratory of Hydraulics and Water Resources, California Institute of Technology, Pasadena, CA, USA, 1984. Report No. KH-R-46.

38. Wang, H.; Law, A.W.-K. Second-order integral model for a round turbulent buoyant jet. J. Fluid Mech. 2002, 459, 397-428. [CrossRef]

Publisher's Note: MDPI stays neutral with regard to jurisdictional claims in published maps and institutional affiliations.

(C) 2020 by the authors. Licensee MDPI, Basel, Switzerland. This article is an open access article distributed under the terms and conditions of the Creative Commons Attribution (CC BY) license (http://creativecommons.org/licenses/by/4.0/). 